\title{
QUANDO SER MENINA É RUIM: PERCEPÇÕES DE GÊNERO EM CRIANÇAS E ADOLESCENTES
}

\author{
CUANDO SER NIÑA ES MALO: \\ PERCEPCIONES DE GÉNERO EN NIÑOS $\Upsilon$ ADOLESCENTES \\ WHEN BEING A GIRL IS BAD: \\ GENDER PERCEPTIONS IN CHILDREN AND ADOLESCENTS
}

\author{
Lêda Gronçalves de Freitas ${ }^{1}$, Benedito Rodrigues dos Santos ${ }^{2}$, \\ Luciana da Silva Santos ${ }^{1}$ e Eloísa Valéria da Silva ${ }^{1}$ \\ ${ }^{1}$ Universidade Católica de Brasília, Brasília/DF, Brasil \\ ${ }^{2}$ International Institute for Child Rights and Development (IICRD), Universidade de Victoria, Canadá
}

\begin{abstract}
RESUMO: Este artigo é um recorte da pesquisa que analisou as percepções de meninas de 6 a 14 anos sobre os aspectos que facilitam e/ou impedem o desenvolvimento de suas habilidades e a garantia de seus direitos a partir do ambiente familiar, escolar, comunitário e social. O estudo teve abordagem plurimetodológica e abrangeu as cinco regiões do Brasil. Em particular, destaca-se a percepção de meninas a partir do exame das respostas a duas questões. Observou-se que as meninas argumentam os aspectos negativos de gênero a partir de quatro grandes fatores: (a) violência sexual, (b) comportamentos e estética, (c) relação com o corpo e sexualidade e (d) responsabilidades e restrição da liberdade. Em todos eles, os discursos das meninas confirmam o quanto as relações de poder são determinantes nas concepções, representações e práticas de gênero ainda hegemônicas na sociedade.
\end{abstract}

PALAVRAS-CHAVE: Meninas; Adolescentes; Estudos feministas; Violência de gênero; Desigualdade de gênero.

RESUMEN: Este artículo es un recorte de la investigación que analizó las percepciones de niñas de 6 a 14 años sobre los aspectos que facilitan y/o impiden el desarrollo de sus habilidades y la garantía de sus derechos, desde el ambiente familiar, escolar, comunitario y social. El estudio tuvo un enfoque plurimetodológico y abarcó las cinco regiones de Brasil. En particular, se destaca la percepción de las niñas a partir del examen de las respuestas a dos cuestiones. Se observó que las niñas argumentan los aspectos negativos de género a partir de cuatro grandes factores: (i) violencia sexual, (ii) comportamientos y estética, (iii) relación con el cuerpo y sexualidad y (iv) responsabilidades y restricción de la libertad. En todos ellos, los discursos de las niñas confirman cuánto las relaciones de poder son determinantes en las concepciones, representaciones y prácticas de género aún hegemónicas en la sociedad.

PALABRAS CLAVE: Niñas; Adolescentes; Estudios feministas; Violencia de género; Desigualdad de género.

ABSTRACT: This article is a clipping of a research that analyzed the perceptions of girls aged 6-14 on the aspects that facilitate and/or prevent the development of their abilities, and the guarantee of their rights, from their family, school, community and social environment. The study had a multi-methodological approach and covered Brazil's five regions. In particular, the girls' perception stands out based on the examination of their answers to two questions. It was observed that the girls argue negative aspects of gender from four big factors: (a) sexual violence, (b) behavior and aesthetics, (c) relations with the body and sexuality, and (d) responsibilities and freedom restriction. In all of them, the girls' discourses confirm how power relations are determinant in the conceptions, representations and practices of gender that are still hegemonic in society.

KEYWORDS: Girls; Adolescents; Feminist studies; Gender violence; Gender inequality. 


\section{Introdução}

A necessidade de se pensar a infância e a adolescência a partir das questões de gênero é o foco deste artigo. Partiu-se do entendimento de Scott (1989) sobre gênero como constitutivo das relações sociais com base nas diferenças entre os sexos e como uma forma primeira de significar relações de poder.

A autora elenca quatro elementos constitutivos das relações sociais fundadas nas diferenças percebidas entre os sexos para definir gênero. O primeiro são os símbolos culturalmente disponíveis que evocam múltiplas representações, muitas vezes contraditórias, como inocência e corrupção, purificação e poluição etc., ou então os clássicos símbolos femininos como Maria, Eva e Afrodite. O segundo elemento são os conceitos normativos que buscam interpretar e limitar as possibilidades metafóricas dos símbolos, como as doutrinas religiosas, jurídicas, científicas etc. Para a autora, tais doutrinas estabelecem a interpretação binária e fechada para significar masculino e feminino. O terceiro é a inclusão da dimensão política à categoria gênero. Mesmo que construído por meio de relações de parentesco, o gênero não pode ficar engessado a isto, tendo como argamassa também a política, a economia, a educação e as relações sociais, que operam de forma independente do parentesco. $\mathrm{O}$ quarto elemento é a identidade subjetiva e diz respeito à distribuição do poder, que se utiliza das diferenças entre os corpos para legitimar controles e acesso diferenciado aos bens materiais e simbólicos. Dessa forma, a conceituação de gênero apontada neste artigo o entende como uma categoria histórica, na qual há uma organização social das desigualdades sexuais estabelecidas (Scott, 1989).

As violências de gênero, sobretudo a sexual, exprimem as formas com que as relações de poder são exercidas. Saffioti (2001) argumenta que a violência de gênero é uma expressão da função patriarcal, na qual os homens detêm o poder de determinar as categorias sociais nomeadas, recebendo autorização ou tolerância da sociedade para punir o que considera desvios. O exercício do mando e do poder pode ser auxiliado pela violência, no qual a autora denomina como projeto de dominação-exploração dos homens.

As mulheres, ainda que não contenham o mesmo projeto na relação com crianças e adolescentes, podem desempenhar, como delegação, a função patriarcal. E o fazem, tanto que o Mapa da Violência - Homicídio de Mulheres no Brasil, elaborado pela Flacso Faculdade Latino-Americana de Ciências Sociais (Waiselfisz, 2015) com base nos dados do Sistema de Notificação de Violências do Ministério da Saúde (2013), aponta que, na fase da infância, a mãe divide com o pai a função de agressora/agressor em $82 \%$ dos casos notificados, sendo que a maior concentração está na mãe (42,4\%) do que no pai (29,4\%). Na adolescência, a figura feminina como agressora diminui e a masculina cresce. Enquanto pais e mães representam, juntos, $26,5 \%$ dos agressores, os parceiros (namorados, ex-namorados, parceiros, ex-parceiros, maridos, ex-maridos) representam 23,2\%.

Saffioti (2001), contudo, afirma que só é possível falar da contribuição das mulheres para a violência de gênero a partir da compreensão da violência simbólica, como define Pierre Bourdieu (1999). Tal violência impregna as categorias sociais dominadas, fornecendo-lhes esquemas cognitivos conforme esta hierarquia. 
Trata-se de fenômeno situado aquém da consciência, o que exclui a possibilidade de se pensar em cumplicidade feminina com homens, no que tange ao recurso à violência para a realização do projeto masculino de dominação-exploração das mulheres. Como o poder masculino atravessa todas as relações sociais, transforma-se em algo objetivo, traduzindo-se em estruturas hierarquizadas, em objetos, em senso comum. (Saffioti, 2001, p. 119)

As violências contra crianças e adolescentes praticadas por familiares, no caso aqui em análise pela mãe, mostram os paradoxos e as complexidades de se entender o fenômeno a partir de uma abordagem de gênero. O levantamento do Mapa da Violência mostra que em todas as etapas da vida preponderam atendimentos femininos no sistema de saúde decorrentes de violências domésticas, sexual e outras. Na violência doméstica a mãe carrega um papel significativo de agressora na fase da infância, reproduzindo a lógica patriarcal que é estrutural na sociedade. Já nas outras fases da vida os homens, em que pese também serem agressores na infância, ganham relevância como os maiores agressores, em especial na violência sexual, demonstrando como exercem a função patriarcal e as relações de poder (Waiselfisz, 2015).

Conforme Waiselfisz, na infância, a proporção de meninas atendidas por casos de violência, segundo o Ministério da Saúde (2013), é de 54,1\%, contra 45,5\% de meninos. Esses percentuais vão aumentando na adolescência, com $65,1 \%$ de meninas contra $34,9 \%$ de meninos, e atingem seu ponto mais alto na idade jovem e adulta, com respectivamente $70 \%$ de mulheres e $30 \%$ de homens e $71,3 \%$ de mulheres e homens.

Santos e Izumino (2005) apontam três fatores explicativos para a violência contra mulher - incluindo aqui as meninas: a primeira considerada como "dominação masculina”, em que a violência se torna a expressão do poder do homem sobre a mulher, que não tem autonomia, sendo identificada como a vítima ou como a cúmplice deste ato; a segunda é a "dominação patriarcal", que tem a mulher como sujeito autônomo e pertencente ao social, mas que em sua história é vitimizada pelo poder masculino, expresso pelo patriarcado; e, por último, a "relacional”, na qual a violência é um meio de comunicação e de jogo entre o homem e a mulher, esta vista como cúmplice.

Saffioti (2001) rebate a visão vitimista construída sobre as mulheres, afirmando que "se a ordem patriarcal de gênero é imposta, não requerendo sequer legitimação, segundo Bourdieu, as mulheres são efetivamente vítimas deste estado-de-coisas” (p. 120). Isso significa que as mulheres não só podem como oferecem resistência ao processo de exploração-dominação, não apenas de gênero, como de raça/etnia e classe.

No caso da infância e adolescência, as construções hegemônicas de gênero - a partir do binarismo e da heteronormatividade - são aprendidas por meninas e meninos, sobretudo por meio de instituições - a exemplo de família, escola, congregações religiosas. E também nesses períodos do desenvolvimento humano em que os estereótipos e a construção de papéis - ditos masculinos e femininos - podem ser contestados.

Swann (1992) afirma que a criança constrói um sistema interno de regras de gênero a partir de sua experiência e das representações disponíveis na cultura a qual está inserida. Por meio da linguagem falada ou imagética, verbal ou escrita, com as quais interage, ela não só aprende expectativas para seu comportamento, mas também pode (re)interpretar tais representações, bem como lhes acionar outros componentes, propondo negociações para novos comportamentos. 
E uma alternativa para adquirir novos comportamentos e para romper com velhos paradigmas de silenciamento frentes às assimetrias de gênero e sua mais extrema expressão, que é a violência contra as mulheres, é a possibilidade da denúncia e do ativismo do movimento feminista no mundo e no Brasil. Tal postura teve como resultado, no país, importantes ganhos do ponto de vista normativo e institucional. Podemos citar, nesse sentido, a criação da Secretaria Especial de Políticas para as Mulheres (SPM) em 2003; a promulgação da Lei n. 11.340/06, conhecida como Lei Maria da Penha; a promulgação da Lei n. 13.104/2015, que prevê o feminicídio como circunstância qualificadora do crime de homicídio e hediondo; a Resolução n. 180 do Conselho Nacional dos Direitos da Criança e do Adolescente (Conanda) em 2016, dispondo sobre os direitos das meninas e recomendando a implementação de ações que visem à igualdade de gênero em todas as políticas, com destaque para as áreas de educação, saúde e assistência social; e a promulgação da Lei n. 13.431/17, determinando um conjunto de ações protetivas para crianças e adolescentes vítimas e/ou testemunhas de violências, sobretudo a violência sexual, evitando-se, assim, os processos de revitimização.

Para mulheres, adolescentes e meninas, tais iniciativas significam proteção e construção - paulatina, constante e vigilante por parte dos agentes sociais e políticos - promovendo outra lógica de gênero nas políticas públicas. Aliado a isso, devemos lembrar que os novos arranjos familiares na sociedade contemporânea podem levar a outras formas de vivenciar e conceituar gênero, podendo ter impacto sobre meninas e meninos.

Dessa forma, neste trabalho, buscou-se compreender como um grupo de crianças e adolescentes meninas caracteriza e verbaliza o que é ser menina para elas, de forma a verificar "como" e "que" construções de gênero moldam seus discursos.

\section{Procedimentos metodológicos}

O presente artigo traz um recorte da pesquisa "Por ser menina: percepções, expectativas, discriminações, barreiras, violências baseadas em gênero e habilidades para a vida das meninas de 6 a 14 anos nas cinco regiões do Brasil”, que teve como foco as percepções das meninas crianças e adolescentes acerca das questões de gênero, relacionando-o com o seu desenvolvimento e os círculos que as envolvem. O estudo envolveu 21 municípios de cinco estados: Pará, Maranhão, São Paulo, Rio Grande do Sul e Mato Grosso (Santos \& Barbieri, 2014).

O estudo combinou métodos quantitativos e qualitativos, abrangendo a aplicação de questionário e a realização de entrevistas individuais e coletivas. O total de participantes foi de 1.931 meninas, sendo que 1.609 compuseram a Amostra-Escola, 149 a Amostra Quilombola e 13 participaram apenas da fase qualitativa para oferecer uma perspectiva do ser menina para aquelas que estavam fora da escola.

A pesquisa foi aprovada pelo Comitê de Ética em Pesquisa (CEP) da Universidade Católica de Brasília, sob o Parecer de n. 346.506. Antes da coleta dos dados, a equipe central da pesquisa realizou um estudo piloto na cidade Brasília. Importante ressaltar que houve toda a implicação das escolas em relação ao Termo de Consentimento Livre e Esclarecido e à Carta de Informação, para a conscientização e disponibilidade voluntária das meninas e adolescente estudantes. 
Procurando dar maior visibilidade e inclusão, houve uma divisão entre as idades, com dois grupos, um de 6 a 10 anos e outro de 11 a 14 anos. Houve ainda uma preocupação em inserir meninas afrodescendentes e quilombolas, além da contemplação de áreas rurais e urbanas para uma melhor representação dos tipos populacionais.

$\mathrm{Na}$ entrevista qualitativa, participaram meninas das três amostras (amostra-escola, amostra-quilombola e amostra meninas fora do contexto escolar), estando incluso as duas divisões feitas com base nas idades, conforme Tabela 1 a seguir.

Tabela 1. Entrevistas qualitativas

\begin{tabular}{|c|c|c|c|c|}
\hline Idade & Amostra-escola & Quilombolas & Meninas fora da escola & Total \\
\hline $\begin{array}{c}\text { Meninas de } \\
6 \text { a } 10 \text { anos }\end{array}$ & 59 & 16 & 0 & 75 \\
\hline $\begin{array}{c}\text { Meninas de } \\
11 \text { a } 14 \text { anos }\end{array}$ & 140 & 49 & 13 & 202 \\
\hline Total & 199 & 65 & 13 & 277 \\
\hline
\end{tabular}

\section{"Elementos do manuscrito"}

Para a definição dos municípios da amostra-escola foi realizado sorteio probabilístico por meio do método AAS (Amostra Aleatória Simples), tendo sido fixado 4 (quatro) em cada Estado. A capital, por sua vez, foi considerada município autorrepresentativo, ou seja, com probabilidade 1 (um) de compor a amostra.

As escolas foram selecionadas por localização (urbano e rural), por dependência administrativa (pública e privada) e por nível de ensino (fundamental 1 e fundamental 2), tendo por base o Censo Escolar de 2012. As escolas sorteadas impossibilitadas de participar da pesquisa foram substituídas por escolas de um cadastro reserva, igualmente sorteadas para esta finalidade.

Correlacionando o tipo de escola com o tipo de amostra das meninas, houve $100 \%$ de predominância das meninas quilombolas nas escolas públicas rurais. Já na amostra-escola, o ambiente escolar utilizado em maior peso foi o público urbano, seguido pelo público rural e, por último, o particular urbano, como mostra a Tabela 2 aqui apresentada.

Tabela 2. Tipos de escolas

\begin{tabular}{|c|c|c|c|c|c|}
\cline { 3 - 6 } \multicolumn{2}{c|}{} & $\begin{array}{c}\text { Escola Pública } \\
\text { Urbana }\end{array}$ & $\begin{array}{c}\text { Escola Pública } \\
\text { Rural }\end{array}$ & $\begin{array}{c}\text { Escola Particular } \\
\text { Urbana }\end{array}$ & Total \\
\hline \multirow{2}{*}{$\begin{array}{c}\text { Amostra } \\
\text {-escola }\end{array}$} & $\mathrm{n}$ & 954 & 378 & 277 & 1609 \\
\cline { 2 - 6 } & $\%$ & $59,3 \%$ & $23,5 \%$ & $17,2 \%$ & $100 \%$ \\
\hline $\begin{array}{c}\text { Amostra } \\
\text { Quilombola }\end{array}$ & $\mathrm{n}$ & 0 & 149 & 0 & 149 \\
\cline { 2 - 6 } & $\%$ & $0,0 \%$ & $100 \%$ & $0,0 \%$ & $100 \%$ \\
\hline
\end{tabular}




\section{"Elementos do manuscrito"}

Decorrente dos métodos de coleta de dados, extraímos os seguintes tópicos para análise no presente artigo: "Existe algo ruim em ser menina?" e "Quando as meninas gostariam de ter nascido menino?". Para a coleta de dados do tópico "Existe algo ruim em ser menina?" foram feitas entrevistas individuais com meninas de 6 a 10 anos e entrevistas coletivas com adolescentes de 11 a 14 anos, contendo as amostras escola, quilombola e meninas fora da escola. Já para o tópico "Quando as meninas gostariam de ter nascido menino?" foram feitas questões abertas a partir da provocação sobre "se nascessem de novo, escolheriam ser menina ou menino”, contendo as amostras escola e quilombola.

Utilizamos a técnica de análise de conteúdo baseada em Bardin (2011), por nos permitir fazer inferências sobre os conhecimentos que surgem a partir das mensagens. Com a expressão do conteúdo identificada é possível começar o processo de análise. Para este artigo propomos sistematizar a análise em quatro categorias, surgidas a partir da análise das falas das meninas: (a) violência sexual, (b) comportamentos e estética, (c) relação com o corpo e a sexualidade e (d) responsabilidades e restrição da liberdade.

\section{Resultados e discussão}

Das respostas dadas à pergunta "Existe algo ruim em ser menina?", 29\% das meninas responderam positivamente. Este percentual, apesar de mais baixo do que as repostas negativas, merece especial atenção, pois aqui se encontram narrativas de vivências e medos que a desigualdade de gênero pode causar. Como mostra a Figura 1:

\section{Figura 1. Existe algo ruim em ser menina?}

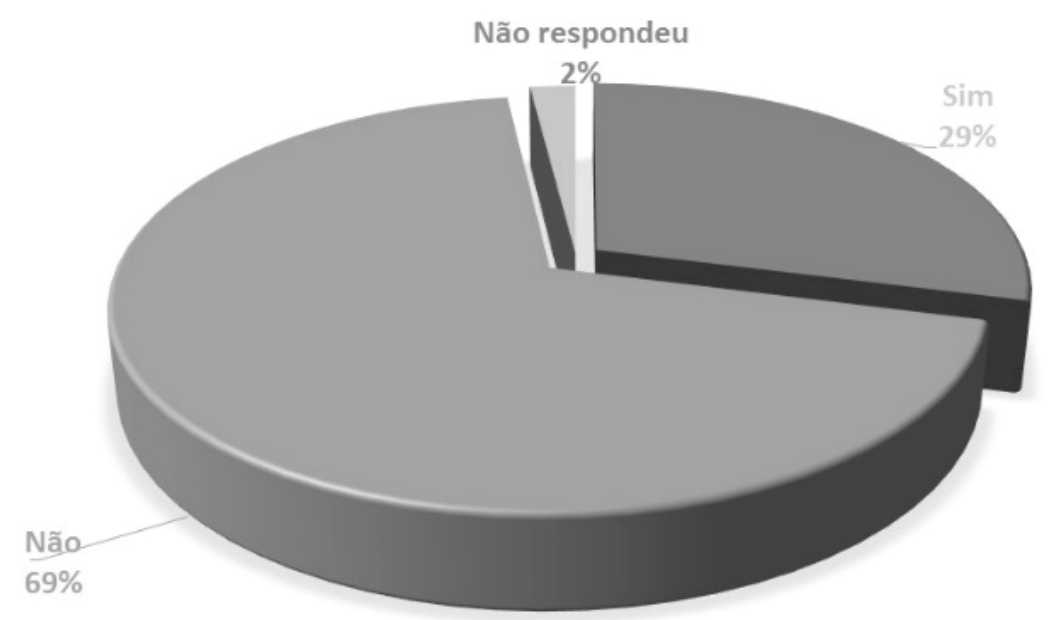




\section{"Elementos do manuscrito"}

Os termos utilizados para responder o motivo de ver o ser menina como algo ruim e que melhor expressam as falas das entrevistadas foram: o medo da violência, os estereótipos comportamentais e estéticos, o preconceito, o tabu sobre o corpo da menina e a troca da liberdade pela responsabilidade. Não muito diferente, na categoria "Quando as meninas gostariam de ter nascido menino”, os argumentos utilizados para manifestar suas respostas foram: menos discriminação em relação à desigualdade de gênero, menos preocupações com o corpo, menor privação de liberdade e responsabilidades (afazeres domésticos). Além disso, elas retrataram diversos motivos pelos quais "ser menino" é melhor do que "ser menina", incluindo a falta de valorização da menina \mulher, a não necessidade de se manter sempre dentro dos padrões de beleza e ter "poder".

\section{Violência sexual}

As entrevistadas elencaram a violência sexual como um fator que as fazem não gostar de serem meninas. Os meninos/homens, além de possuírem mais vantagens no campo da sexualidade e dos relacionamentos, são vistos como algozes em relação a esse tipo de violência contra elas.

Algo de ruim existe. Porque você pode ser violentada, pode ser morta, por algum assassino, entendeu? Por algum homem e pode ser também, ele pode abusar assim de você, é isso. (10 anos, SP)

As ruins, eu acho que é o assédio dos meninos. (9 anos, SP)

Vai você está andando na rua aí passa um cara e ele buzina para você. Manda você entrar. Se uma menina ficar com um menino. Nossa, é puta, é vadia, é tudo. Mas se o menino fica com várias meninas, nossa é o pegador. É o gostoso. Exatamente. Parece que você está numa prateleira. Que todas nós estamos em uma prateleira e ele pega, escolhe, compra e depois devolve. (10 anos, MA)

Essa percepção das meninas das violências de gênero, em especial a sexual, reforça os dados sobre a ocorrência do fenômeno no país. As meninas, segundo os dados estatísticos do Ministério da Saúde (2013), são mais acometidas pelos quatro tipos de violência mais recorrentes nas denúncias e notificações: física, sexual, psicológica e negligência/abandono.

O discurso das entrevistadas demonstra a permanência do papel dicotômico de gênero no qual o masculino é representado pela agressão e domínio e o feminino pela passividade e subjugação. Esses papéis delimitados, a exemplo do que Bourdieu (1999) expõe, explica como esses esquemas são construídos nos corpos socializados, numa confirmação natural de hierarquia binária que encontra eco em quase toda parte, por meio do social, e naturalizada pelas posições homólogas de homem-mulher e das atribuições que são dadas a essas divisões: alto-baixo, forte-fraco, em cima-embaixo, frente-atrás, público-privado etc.

As falas demonstram ainda que a função patriarcal e seu aparato violento, como afirma Saffioti (2001), é aprendida desde muito cedo. Aparentemente, as participantes da pesquisa compreendem que nesse exercício da função patriarcal os homens/meninos manifestam o poder, e sua capacidade de mando auxiliada pela violência na execução do projeto 
de dominação-exploração, enquanto discurso normativo de papéis familiares. Papéis esses que sinalizam uma posição de impotência do feminino, uma vez que valores patriarcais são perpassados entre as gerações, deixando suas marcas e valores na constituição de muitas instituições - inclusive familiares.

Essa percepção de dominação é o símbolo (Scott, 1989) acionado pelas meninas como o da coisa ("parece que você está numa prateleira”), evocando um significado cultural da mulher objeto, a ser utilizada de forma dominante pelos meninos ("ele pega, escolhe, compra e depois devolve”). Revela ainda uma concepção e uma prática de gênero bastante preocupante por parte dos meninos, cujo aprendizado não se dá de forma isolada, mas aprendida a partir das representações e exemplos disponíveis na cultura na qual estão inseridos (Swann, 1992). Com base nisso, podemos inferir que o contexto familiar, comunitário e social desses meninos tem colaborado para moldar seus comportamentos.

Medo, apreensão e ressentimento são entrevistos nas falas das meninas e formam os componentes para justificar a negação do feminino, do ser menina. É tão ruim ser menina nesse sentido que melhor seria nascer homem, em que pese elas não mostrarem empatia alguma por esse tipo de homem. Essa percepção foi proposta por Scott (2005) ao afirmar que esse domínio gerado no feminino é de tal ordem que quando se busca eliminar as desigualdades entre os sexos, acaba-se encontrando nos discursos uma tentativa de igualar-se ao gênero oposto, dominador.

\section{Comportamentos e estética}

Nesta categoria, reunimos os argumentos das meninas relacionados a: comportamentos esperados para elas pelo padrão tradicional de gênero, artefatos culturais também divididos pelo binarismo pode/não pode a partir do sexo biológico e questões estéticas. Neste último caso, vemos o quanto elas são perpassadas por outras questões como raça.

Nesse sentido, ser menina é ruim quando sentem que estão em posição inferior aos meninos, pois não podem fazer coisas que eles fazem, como: se comportar como quer, praticar esportes e brincar do que gosta, usar o que gosta etc.

Às vezes seu pai não deixa você fazer uma coisa, fica "ai você é menina, não sabe se comportar com saia. É por isso que você não usa”. É não poder fazer as coisas que você quer, menino pode mais e às vezes menina não pode e às vezes é uma coisa que você gosta andar de skate. Ninguém da minha família anda de skate, então eu acho que eles não gostam, só que eu gostaria muito de andar de skate. No futuro, às vezes, eu vou pedir para meus pais quando eles tiverem condições financeiras para eles me colocarem numa aula de skate. (8 anos, $\mathrm{SP}$ )

Só uma coisa: os meninos podem brincar e as meninas não. Na minha casa ninguém pode brincar, só os meninos. Porque os meninos são melhores que as meninas e elas são um pouco melhores que os meninos. Não podem passar a minha maquiagem e também não podem me bater porque sempre me batem. As meninas não podem brincar de bola e a gente não pode de vôlei, e a gente não pode esconde-esconde, eles não deixam a gente brincar. (9 anos, SP) 
Estética sofre muito preconceito. Na cor, no cabelo, na altura, na roupa, tudo. (10 anos, MA) É bem assim... Uma coisa ruim também é cortar cabelo, eu gosto do meu cabelo até na altura do peito, mas minha mãe sempre fala para eu cortar, diz que meu cabelo é muito duro, mas eu não gosto de cortá-lo. (10 anos, SP)

O discurso das meninas, nesse caso, demonstra como as relações de poder construídas historicamente são simbolizadas e recebem prescrições rígidas para se evitar fugas (Scott, 1989). Os familiares prescrevem normas para comportamentos, brincadeiras, jogos e artefatos culturais que podem utilizar ou, neste caso, não podem, na maioria das falas, utilizar. São falas ressentidas que apontam para preconcepções arraigadas no contexto cultural brasileiro e que expressam rótulos consolidados das características convenientes para meninas e meninos. As meninas simbolizam de muitas maneiras, como no skate, na saia e na maquiagem, que representam artefatos culturais acionados para expressar as diferenças de gênero. Assim, utilizando a linguagem, produzem discursos que demonstram todo o incômodo com as restrições e interditos que sofrem por serem meninas. Uma das restrições mais significativas no contexto em análise é "não poder brincar". Tal negativa vai de encontro ao significado que a infância ganhou na modernidade, que é justamente o tempo para brincar e estudar (Ariès, 2012). Essa fala revela que a categoria infância precisa ser analisada também em cruzamento com a categoria gênero, pois que a segunda pode (re)configurar a primeira.

Em relação à estética, há uma fala explícita sobre preconceito e outra na qual ele pode ser lido nas entrelinhas: "minha mãe sempre fala para eu cortar, pois meu cabelo é muito duro”. Saffioti (1997) afirma que gênero, raça e classe não podem ser concebidos como três dimensões de ordenamentos sociais que correm em paralelo. Ao contrário, entrelaçam-se para formar um nó, em que pese sua junção não dilua suas diferenças e contradições.

Dessa forma, é preciso avaliar esse fenômeno em sua interseccionalidade, porque o ruim de ser menina é perpassado também pela cor, nos hábitos e representações estéticas da sociedade - como afirma uma das meninas entrevistadas. Ela demonstra um somatório de características (cor, cabelo, altura) que tornam o ser menina uma realidade de difícil vivência. As especificidades, nesse caso, são vistas como desviante da ordem vigente, ordem essa não só de gênero, mas de raça, de classe e de padrão estético.

\section{Relação com o corpo e a sexualidade}

A percepção do corpo, ou melhor, a falta de percepção, foi outro argumento utilizado pelas entrevistadas para descrever o lado ruim de ser menina. A passagem da infância para a adolescência e a menarca são momentos apontados por elas de estranhamento e de difícil vivência. Aliado a isso está a interdição da família sobre o diálogo acerca da sexualidade.

Tem várias. Eu só falei que tem várias. Se desenvolver rápido. É um susto isso. É um susto! Porque você dormiu e... É estranho... Com 9 anos você dormiu de um jeito e parece que você acordou e você já tem pelos. O seu corpo todo. O seu peito cresceu. Gente que aconteceu comigo? Ai do nada, você acorda num dia e sua calcinha está vermelha. "O que é isso?". É um susto! (9 anos, PA) 
Antes não tinha esse corpo que todo mundo tem. Podia andar só de calcinha, de blusa sem sutiã. Porque eu não gosto de andar sem sutiã, nem quando estou em casa, pois acho muito esquisito uma menina sem sutiã. E para mim ficou ruim nessa parte também. (PU, MT)

O estranhamento, o desconhecimento e o desconforto foram elementos do discurso das meninas, revelando que a relação delas com seu próprio corpo e sexualidade era muito pequeno ou ruim. Se tomarmos como parâmetro as instituições mais presentes na vida de crianças e adolescentes, a família e a escola, vemos o quanto o tema da sexualidade ainda é um tabu, ao ponto de as meninas terem dificuldade de manejo e entendimento, por exemplo, sobre a menarca, as mudanças hormonais e corporais.

Muitas famílias, seja por questões morais e/ou religiosas, interditam o tema da sexualidade junto a seus filhos, que acabam com conhecimentos muito fragmentados sobre esse tema. E isso gera uma situação paradoxal, pois o silenciamento familiar é contraposto pela farta narrativa midiática que a sexualidade conta. O que não pode ser dialogado em família o é entre os pares, bem como é informado pela internet, TV e outras mídias (Heilborn, 2012).

O corpo demonstra ser ainda o lugar do segredo e do oculto ("eu não gosto de andar sem sutiã", "acho muito esquisito uma menina sem sutiã"). É algo que precisa ser guardado, sob pena de uma exposição revelar um comportamento não esperado para meninas. No caso dessa fala, podemos depreender que usar sutiã pode representar uma perda da liberdade do corpo e da sexualidade que se tinha na infância ("a gente podia andar de blusa sem sutiã”) e uma conformação de gênero no qual o sexo está, para as meninas/mulheres, subjugado de acordo com normas morais muito rígidas.

É simbólico o sutiã aparecer como corporificação do que é ruim em ser menina. Esta peça foi, para o movimento feminista dos anos 1980, o símbolo da opressão e das amarras históricas do corpo e da sexualidade das mulheres e, por isso, queimado em praça pública. Quase 40 anos depois ainda persiste nesse mesmo papel com algumas meninas.

\section{Responsabilidades e restrição da liberdade}

Especialmente no grupo das adolescentes apareceu como argumento negativo para o ser menina a gradual substituição da liberdade pelas responsabilidades, sobretudo domésticas. Esta é uma diferença crucial para as meninas em relação aos meninos, com vantagens para eles, significando, neste caso, uma justificativa para "gostar de nascer menino".

Uma coisa ruim que eu acho da adolescência é que quando eu era menor não precisava fazer muita coisa em casa, não precisava fazer quase nada, só comia, dormia e não queria saber de mais nada. Agora na adolescência tenho sempre de ter consciência de que tenho de chegar em casa e ajudar, se comer tenho de lavar a louça e secar, tenho sempre de estar em função de alguma coisa em casa. (10 anos, PA)

Tem muita gente que fala que a adolescência é a fase do não pode. A pessoa quer namorar com o menino, mas o pai não deixa, nem a mãe. Então tem de namorar escondido porque eles não querem deixar. Falam que quando a gente quiser namorar tem de falar, mas nem sempre temos coragem, e quando temos coragem de falar também não deixam, não querem porque dizem que estamos muito novas, só podendo namorar com 15 anos. (PU, MT) 
Sim [várias vozes]. Nós meninas temos mais preocupações com a vida, essas coisas. Temos de nos cuidar mais de nós e dos estudos, temos que nos preservar, existem alguns tipos de preocupações que nós meninas temos mais que os meninos. Eu acho que sim, são as transformações, porque achamos que estamos prontas para isso, mas a gente não quer. (9 anos, SP)

As desigualdades de gênero podem ser percebidas aqui no acesso diferenciado aos espaços públicos e privados, tributando aos meninos o primeiro e às meninas o segundo. $\mathrm{O}$ espaço privado é historicamente das mulheres, bem como as tarefas que nele se desenvolvem, como as atividades domésticas e o cuidado com os filhos. Para Bourdieu (1999), essa ordem social - que justifica as divergências por uma percepção das diferenças biológicas/genitais e que divide os espaços reservados a cada sexo e a sexualidade destes - leva à incorporação da dominação inscrita nos rituais e a uma divisão sexual do trabalho de produção, de reprodução biológica e social conferindo aos homens a melhor parte, o habitus objetivado.

A mitificação dos papéis da mulher como dona de casa, como mãe, como responsável pela família, pelo cuidado com o esposo, pela educação dos(as) filhos(as) e pelos gerenciamentos dos afazeres domésticos, foi uma construção social que enrijeceu a condição feminina e, mais do que isso, impossibilitou ou desqualificou sua inserção em outros espaços - tema percebido e apontado pelas meninas entrevistadas por sentirem sua liberdade limitada às "condições" femininas, provavelmente por já se sentirem responsáveis pelo espaço doméstico.

Responsabilidade esta muitas vezes imposta pelas organizações familiares e processos de socialização e modelagem, ou até mesmo por realidades econômicas reais, uma vez que o Fórum Nacional de Prevenção e Erradicação do Trabalho Infantil (2015) aponta que "Das crianças e adolescentes ocupados no Brasil em 2013, 64,7\% (2,06 milhões) eram do sexo masculino e 33,3\% (1,12 milhão) do sexo feminino"(p. 20). O que indica, ainda, que a permanência das meninas no ambiente privado e doméstico é, segundo Braslasvkli (1985), a persistência da "domesticidade excludente" para o público feminino, marcada desde os ciclos iniciais de vida.

É também importante frisar que as meninas se ressentem de que a liberdade delas vai sendo ainda mais privada quando chegam à adolescência. Elas têm menos permissão para sair, passear e namorar que os meninos. As famílias, nesse caso, colaboram para a manutenção do sexo feminino confinado no ambiente doméstico. As razões para essa restrição podem ser medo da violência e de vivência da sexualidade. Assim, familiares acabam restringindo a vida comunitária e social das meninas, criando um ambiente opressivo para elas. 


\section{Considerações finais}

Neste artigo analisamos as percepções de meninas e adolescente de 6 a 14 anos sobre o que é ruim em ser menina. Pelos resultados, percebemos que a violência sexual é uma questão sensível para as meninas, que notam, nesse aspecto, dois posicionamentos superiores dos meninos: vantagens em relação à sexualidade e relacionamentos e afirmação do padrão patriarcal no qual a violência é uma prática autorizada.

Os papéis tradicionais de gênero são esperados delas no comportamento e na estética. As meninas utilizam artefatos culturais como skate, saia e maquiagem para simbolizar as relações dicotômicas e afirmar o quanto as normas, sobretudo familiares, limitam suas possibilidades de construir outros símbolos ou novas funções para os mesmos símbolos. Há ainda uma percepção ruim de ser menina relacionada às questões raciais, demonstrando o quanto as categorias gênero e raça se cruzam na conformação das desigualdades.

O corpo é um território desconhecido para algumas meninas, sobretudo na fase de transição entre a infância e a adolescência. A menarca e as mudanças inerentes ao processo de amadurecimento biológico do corpo são motivo de desconforto e estranhamento. Inferimos que o tema da sexualidade pode ser interditado pelas famílias, fazendo com que as meninas tenham dificuldade de lidar, aceitar e experimentar seus próprios corpos como expressão de gênero. Por fim, o processo de adolescer é apontado, por elas, como de perda da liberdade, aumento de responsabilidades domésticas e de maior confinamento no espaço doméstico.

Os argumentos das meninas quanto aos aspectos ruins em ser menina mostram o quanto as relações de poder são significativas para a compreensão de gênero. Poder, no discurso delas, produzido por muitos agentes, como meninos, pais, mães e sociedade. O padrão dicotômico e os papéis de gênero, bastante definidos pela normatização biológica, fazem parte da sua vivência e certamente estão ajudando a construir seu aprendizado.

No entanto, é preciso apostar na capacidade transgressora e de resistência das meninas e mulheres, como apontam muitas estudiosas feministas. Gênero é uma categoria histórica, complexa e dinâmica, e as meninas podem construir novas interpretações e práticas para ela. Não à toa, outras $69 \%$ das meninas não veem coisas ruins em ser menina. E estas, que têm visão positiva sobre gênero, estão no mesmo espaço de convivência das 29\% que têm visão negativa. Isso pode ser uma forma de abertura para novos diálogos entre as meninas, ajudando a (re)configurar o gênero em suas vidas. 


\section{Referências}

Ariès, Phillipe. (2012). História social da criança e da família (2a ed., reimpr.). Rio de Janeiro: LTC. Bardin, Laurence. (2011). Análise de conteúdo. São Paulo: Edições 70.

Bourdieu, Pierre. (1999). A dominação masculina. Rio de Janeiro: Bertrand Brasil.

Braslasvky, Cecília. (1985). La discriminación educativa enem la Argentina. Buenos Aires: FLACSO; Miño y Dávila.

Fórum Nacional de Prevenção e Erradicação do Trabalho Infantil (FNPETI). (2015). Trabalho infantil e trabalho doméstico no Brasil: Avaliação a partir dos microdados da Pnad/IBGE (2012-2013). Brasília, DF: Autor. Recuperado de < https://fnpeti.org.br/media/publicacoes/ arquivo/Trabalho Infantil e Trabalho Infantil Domestico no Brasil 2012 - 2013.pdf $>$

Heillborn, Maria Luíza. (2012). "Por uma agenda positiva dos direitos sexuais da adolescência”. Psic. Clin., Rio de Janeiro, 24(1), 57-68.

Ministério da Saúde. (2013). Secretaria de Vigilância em Saúde. Departamento de Vigilância de Doenças e Agravos não Transmissíveis e Promoção da Saúde. Sistema de Vigilância de Violências e Acidentes (Viva): 2009, 2010 e 2011 . Brasília, DF: Autor. Recuperado de http://bvsms. saude.gov.br/bvs/publicacoes/sistema vigilancia violencia acidentes.pdf

Saffioti, Heleieth. (1997). Violência de gênero: o lugar da práxis na construção da subjetividade. Lutas Sociais, São Paulo, 2, 59-79.

Saffioti, Heleieth. (2001). Contribuições feministas para o estudo da violência de gênero. Cadernos Pagu, 16, 115-136.

Santos, Benedito. R. \& Barbieri, Paola. (2014). Relatório final da pesquisa: "Por ser menina: percepções, expectativas, discriminações, barreiras, violências baseadas em gênero e habilidades para a vida das meninas de 6 a 14 anos nas cinco regiões do Brasil - Dimensão quantiqualitativa.” v. 1. Brasília, DF: PlanBrasil; Socializare; UCB. (Contribuições de Diana Barbosa e Marli Coriolano).

Santos, Cecília \& Izumino, Wânia. (2005). Violência contra as mulheres e violência de gênero: notas sobre estudos feministas no Brasil. Recuperado de < http://www.nevusp.org/downloads/down083.pdf>

Scott, Joan. (1989). Gênero: uma categoria útil para análise histórica. Recuperado de $<\underline{\mathrm{https}} / / /$ edisciplinas.usp.br/pluginfile.php/185058/mod resource/content/2/G\%C3\%AAnero-Joan\%20Scott.pdf>

Scott, Joan. (2005). O enigma da igualdade. Estudos Feministas, 13(1), 11-30.

Swann, Joan. (1992). Girls, boys and language. Oxford/Besil: Backwell.

Waiselfisz, Julio. (2015). Mapa da violência 2015: homicídio de mulheres no Brasil. Brasília, DF: FLACSO. Recuperado de < http://www.mapadaviolencia.org.br/pdf2015/MapaViolencia 2015 mulheres.pdf $>$ 


\section{LÊDA GONÇALVES DE FREITAS \\ https://orcid.org/0000-0002-1288-7134}

Pós-doutorado no CNAM (Paris, 2017), Doutora em Psicologia Social e do Trabalho (UnB), Mestre em Educação. Professora titular da Universidade Católica de Brasília no Programa de Pós em Psicologia.

Endereço: QS 07, Lote 01, EPCT, Taguatinga - Brasília/DF - CEP 71966-700

E-mail: ledagfr@gmail.com

\section{BENEDITO RODRIGUES DOS SANTOS}

http://orcid.org/0000-0001-7860-1998

Mestre em Ciências Sociais Antropologia pela Pontifícia Universidade Católica de São Paulo (1996), doutorado em Antropologia pela Universidade da Califórnia Berkeley (2002), pós-doutorado pelas universidades Johns Hopkins (2005) e da Califórnia em Los Angeles (2006). Pesquisador associado do International Institute for Child Rights and Development (IICRD), Universidade de Victoria, Canadá.

E-mail: benedito.santos.br@gmail.com

\section{LUCIANA DA SILVA SANTOS}

http://orcid.org/0000-0002-2280-3483

Docente do curso de Pós-graduação Stricto Sensu em Psicologia da Universidade Católica de Brasília. Doutora (2014) e Mestre (2008) pelo Programa de Pós-Graduação em Psicologia Clínica e Cultura da Universidade de Brasília. É coordenadora da pesquisa Violência(s) contra as mulheres donas-de-casa: Ausência de direitos e impactos na saúde mental - VISMM, financiada pela Fundação de Apoio à Pesquisa (FAP-DF).

E-mail: lucianasantospsi@gmail.com

\section{ELOÍSA VALÉRIA DA SILVA}

https://orcid.org/0000-0001-5864-7745]

Graduanda em Psicologia na Universidade Católica de Brasília.

E-mail: eloisa.valerias@gmail.com 


\begin{tabular}{|c|c|}
\hline Histórico & $\begin{array}{l}\text { Sulbmissão: 11/07/2019 } \\
\text { Aceite: } 21 / 04 / 2020\end{array}$ \\
\hline $\begin{array}{l}\text { Contribuição } \\
\text { dos autores }\end{array}$ & $\begin{array}{l}\text { Concepção: L.G.F., B.R.S. } \\
\text { Coleta de dados: E.V.S.; L.G.F. } \\
\text { Análise de dados: L.G.F.; L.S.S., B.R.S., E.V. } \\
\text { Elaboração do manuscrito: L.G.F.; L.S.S., B.R.S., E.V.S. } \\
\text { Revisões críticas de conteúdo intelectual importante: } \\
\text { L.S.S.; L.G.F. } \\
\text { Aprovação final do manuscrito: L.G.F.; L.S.S., B.R.S., E.V.S. }\end{array}$ \\
\hline $\begin{array}{l}\text { Consentimento } \\
\text { de uso de imagem }\end{array}$ & Não se aplica. \\
\hline $\begin{array}{l}\text { Aprovação, ética } \\
\text { e consentimento }\end{array}$ & $\begin{array}{l}\text { O estudo foi aprovado pelo Comitê de Ética em Pesquisa da Universidade } \\
\text { Católica de Brasília, CAAE: } 176282 \text { 13.6.0000.0029, Número do Parecer: } \\
\text { 346.506. }\end{array}$ \\
\hline Financiamento & $\begin{array}{l}\text { Projeto de Pesquisa: "Orgulho de ser menina": construindo gênero } \\
\text { em contexto de desigualdades, aprovado pelo Edital Chamada MCTI/ } \\
\text { CNPQ/MEC/CAPES No } 22 / 2014 \text { - Ciências Humanas, Sociais e Sociais } \\
\text { Aplicadas, No do Processo: } 471541 / 2014-1 \text {. } \\
\text { Eloísa Valéria da Silva - Bolsista de PIBIC CNPq 471541/2014-1. }\end{array}$ \\
\hline
\end{tabular}

